\title{
Suppressive effect of melatonin on osteoclast function via osteocyte calcitonin
}

\author{
Masaki Nakano1,2, Mika Ikegame³, Junko Igarashi-Migitaka4, Yusuke Maruyama', Nobuo Suzuki ${ }^{5}$ and \\ Atsuhiko Hattori1 \\ 1Department of Biology, College of Liberal Arts and Sciences, Tokyo Medical and Dental University, Chiba, Japan \\ 2Department of Biology, Faculty of Science, Toho University, Chiba, Japan \\ ${ }^{3}$ Department of Oral Morphology, Graduate School of Medicine, Dentistry and Pharmaceutical Sciences, Okayama University, Okayama, Japan \\ ${ }^{4}$ Department of Anatomy and Cell Biology, St. Marianna University School of Medicine, Kawasaki, Japan \\ ${ }^{5}$ Noto Marine Laboratory, Institute of Nature and Environmental Technology, Kanazawa University, Ishikawa, Japan \\ Correspondence should be addressed to A Hattori: ahattori.las@tmd.ac.jp
}

\begin{abstract}
Many studies have investigated the actions of melatonin on osteoblasts and osteoclasts. However, the underlying mechanisms, especially regarding osteocyte function, remain largely unknown. Therefore, this study aimed to clarify the underlying mechanisms of melatonin action on bone tissue via osteocyte function. Chick calvariae were employed as a model. In ovo injection of melatonin $(5,50$ and $500 \mu \mathrm{g})$ dose-dependently decreased the mRNA expression levels of cathepsin K and matrix metalloproteinase 9 (MMP9) in chick calvariae without affecting the expression levels of receptor activator of NF-kB ligand or osteoprotegerin. Surprisingly enough, the expression of calcitonin mRNA in chick calvariae was significantly raised. After 3 days of in vitro treatment of melatonin $\left(10^{-7}\right.$ and $\left.10^{-5} \mathrm{M}\right)$ on newly hatched chick calvariae, both calcitonin mRNA expression in calvariae and the concentration of calcitonin in cultured medium were augmented in a dose-dependent manner, coincident with the decreased mRNA expression levels of cathepsin K and MMP9. Immunohistochemical analyses revealed expression of melatonin receptors and calcitonin by osteocytes buried in bone matrix. Moreover, the mRNA expression levels of melatonin receptors, calcitonin and sclerostin (a marker of osteocyte), were strongly and positively correlated. In conclusion, we demonstrated the expression of melatonin receptors and calcitonin expression in osteocytes for the first time and suggest a new mechanism underlying the suppressive effect of melatonin on osteoclasts via upregulation of calcitonin secretion by osteocytes.
\end{abstract}

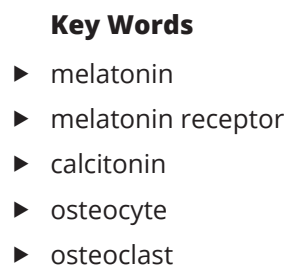

Journal of Endocrinology (2019) 242, 13-23

\section{Introduction}

Melatonin (N-acetyl-5-methoxytryptamine) is an endogenous hormone mainly synthesised in the vertebrate pineal gland in response to darkness (Reiter 1991) and circulating levels exhibit a conspicuous circadian rhythm (Reiter 1993). This amine hormone is known to be involved in several physiological functions, which include immune response (Szczepanik 2007,
Cardinali et al. 2008), energy metabolism (Srinivasan et al. 2013, Kumar Jha et al. 2015) and bone turnover (Amstrup et al. 2013). Another amine hormone, calcitonin, an osteoclast-suppressing hormone, is primarily secreted by $\mathrm{C}$ cells of the thyroid gland in mammals or the ultimobranchial gland in lower vertebrates, including chickens. 
Bone tissue is composed of three types of component cells, osteoclasts, osteoblasts and osteocytes, and an intercellular matrix consisting of type I collagen and hydroxyapatite. Osteocytes are the predominant cell type in bone tissue, accounting for more than 90\%, and are also very long-lived (Knothe Tate et al. 2004, Franz-Odendaal et al. 2006). The osteocytes are terminally differentiated osteoblasts that become trapped and buried in the bone matrix that is self-secreted. These cells possess a number of cellular processes in canaliculae that extend throughout the bone tissue and are connected with each other and/or with other cell types on the bone surface.

Many studies have investigated the action of melatonin on osteoblasts. In human mesenchymal stem cells and mouse pre-osteoblastic MC3T3-E1 cells, melatonin enhances the expression of runt-related transcription factor 2 and bone morphogenetic proteins 2 and 4 (Zhang et al. 2010, Park et al. 2011). Alkaline phosphatase (ALP) and osteocalcin synthesis is reportedly upregulated by melatonin treatment in several osteoblastic cell lines (Roth et al. 1999, Radio et al. 2006) and human primary osteoblasts (Satomura et al. 2007). Besides, melatonin treatment was found to decrease the expression of receptor activator of NF-KB ligand (RANKL), while elevating osteoprotegerin (OPG) expression (Koyama et al. 2002, Histing et al. 2012). Thus, melatonin prevents osteoclast differentiation and activation, and may inhibit bone resorption. Moreover, it is also reported that knockout of MT2, a melatonin membrane receptor, reduced the bone mass of mice, as compared to the wild type (Sharan et al. 2017). In addition, we demonstrate a suppressive effect of melatonin on the activity of osteoclasts using cultured fish scales as a model of membrane bone (Suzuki \& Hattori 2002). This is the first report related to melatonin function directly on osteoclasts in any vertebrate species.

The relationships between the pineal gland and bone tissue are well documented. For instance, spinal malformations have been reported in pinealectomised chickens (Machida et al. 1993, Katoh \& Hattori 1995, Turgut et al. 2005), rats (Machida et al. 1999) and Atlantic salmon (Fjelldal et al. 2004). An experimental chicken model of scoliosis was developed by surgical ablation of the pineal gland and displayed pathoanatomical features similar to those of human idiopathic scoliosis. Furthermore, the experimental model raised by pinealectomy of newly hatched chicks developed symptoms of osteoporosis characterised by bone loss associated with scoliosis (Turgut et al. 2005, Aota et al. 2013). On the other hand, studies in calcitonin of $\mathrm{C}$ cells reported that removal of the pineal gland in rats increased the number of $\mathrm{C}$ cells
(Csaba \& Baráth 1974) and increased the content of endoplasmic reticulum and the number of secretary granules (Csaba \& Baráth 1975). Hence, calcitonin may possibly be a mediator between melatonin and bone metabolism.

To date, calcitonin production has been validated in brain, pituitary, liver, lung and kidney of mammals including humans (Deftos et al. 1980, Flynn et al. 1981, Russwurm et al. 2001) and also in the brain and pituitary gland of avian species (Galan Galan et al. 1981, Maddineni et al. 2007). In the present study, we focused on calcitonin production in osteocytes and its regulation by melatonin. Therefore, we used chick calvariae, which are thought to be a more pure bone tissue with less bone marrow. Here we report the expression of the melatonin receptors and calcitonin in osteocytes for the first time and suggest a new mechanism for the suppressive effect of melatonin on osteoclast function via upregulation of calcitonin secretion by osteocytes.

\section{Materials and methods}

\section{Animals}

Inseminated eggs and newly hatched broiler chicks (Gallus gallus domesticus) were purchased from commercial sources. Inseminated eggs were incubated at $37.8^{\circ} \mathrm{C}$ with automatic turning (once per hour) and newly hatched chicks were housed in a cage maintained at $34 \pm 1^{\circ} \mathrm{C}$ under constant light until euthanised. Calvariae at embryonic day 14-20 (E14-E20) after the start of incubation and those of newly hatched chicks were used for the experiments. The protocols of all animal experiments were approved by the Institutional Animal Care and Use Committee of Tokyo Medical and Dental University (Tokyo, Japan) and were conducted by authorised investigators.

\section{Gene expression patterns in chick calvariae during embryonic development}

Calvariae of E14, E16, E18 and E20 embryos were collected and the periosteum was removed in phosphate-buffered saline $(\mathrm{pH}$ 7.4). The obtained calvariae were crushed in Lysing Matrix K using a FastPrep-24 Instrument (MP Biomedicals, Santa Ana, CA, USA). Then, total RNA was extracted using Isogen reagent (Nippon Gene, Tokyo, Japan) in accordance with the manufacturer's instructions.

Total RNA (1 $\mu \mathrm{g})$ was reverse-transcribed using PrimeScript Reverse Transcriptase and oligo dT primers (Takara Bio). Reverse transcription-polymerase chain 
Table 1 Oligonucleotide sequences of primers used for chick RT-PCR and real-time RT-PCR.

\begin{tabular}{l}
\hline Name (accession no.) \\
\hline GAPDH (NM_204305) \\
Mel1a (NM_205362) \\
Mel1b (NM_001293103) \\
Mel1c (NM_205361) \\
Osteocalcin (NM_205387) \\
ALP (NM_205360) \\
Sclerostin (XM_427339) \\
DMP1 (NM_206993) \\
MEPE (NM_204569) \\
Cathepsin K (NM_204971) \\
MMP9 (NM_204667) \\
RANKL (NM_001083361) \\
OPG (NM_001033641) \\
Calcitonin (NM_001113708)
\end{tabular}

\begin{tabular}{l}
\hline Forward primer $\left(5^{\prime}-3^{\prime}\right)$ \\
\hline ACTTTGGCATTGTGGAGGGT \\
AGCCACCATCCTCATCTTCAC \\
GCAAGCTCAGGAACTCAGGTAA \\
TGGCTCCTTGCAGTATGACC \\
AAAGCCTTCATCTCCCACCG \\
CCAAGAACCTCATCCTCTTCC \\
TCCCCGAGATCACCGAAAAC \\
ACACGCTTCTACACCTCTGC \\
CAGGACGGTGAAACACATATCTC \\
GGTGTACTGCGTCTCCAACA \\
TCGTCCTTCTGGAAATCAGG \\
TGTTGGCTCTGATGCTTGTC \\
GTTTGCAGTTCCTACTCGTTCC \\
CCAGTCTGAGTACTTGTGTGCTG
\end{tabular}

\begin{tabular}{l}
\hline Reverse primer $\left(5^{\prime}\right.$-3') $\left.^{\prime}\right)$ \\
\hline ACGCTGGGATGATGTTCTGG \\
TATATTTCCCGCGTTCCGCA \\
GCATTTCACCCAAAGTCCATCC \\
AAGTCACGATGGACAGTGGG \\
CAGCTCACACACCTCTCGTT \\
GGGAACTTGTCCATCTCCAG \\
AGTGTGTGGTGTATGTGCCTT \\
TGCTGCATCCTCAGGCTCT \\
TGACATTGGCCTCACTGGTAG \\
CATACAGCTCTCATCCTGCCC \\
TCTTGGTGAGCACATCTTGG \\
GCTTCTGGCTCTCAATCTTCTC \\
TCAAAAGCTGGAAGGTCTGC \\
AGGGTTTCCCCATAGTTTGC
\end{tabular}

reaction (RT-PCR) amplifications were performed with Ex Taq DNA Polymerase (Takara Bio) and primers for chicken melatonin receptors (mel1a, mel1b and mel1c) and glyceraldehyde-3-phosphate dehydrogenase (GAPDH), as an internal control (Table 1), using cDNA generated from the cerebral and calvarial tissues of E20 embryos as templates. The conditions for RT-PCR were 35 cycles of denaturation for $30 \mathrm{~s}$ at $94^{\circ} \mathrm{C}$, annealing for $30 \mathrm{~s}$ at $60^{\circ} \mathrm{C}$ and extension for $1 \mathrm{~min}$ at $72^{\circ} \mathrm{C}$. PCR products were analysed by electrophoresis on $2 \%$ agarose gels, containing Tris base, acetic acid and ethylenediaminetetraacetic acid (EDTA), which were then stained with ethidium bromide. There were no amplified products when using the reverse-transcription-omitted samples as a negative control.

To investigate mRNA expression levels in chick calvariae during embryonic development, real-time RT-PCR was performed using primers for the melatonin receptors mel1a and mel1c, the bone-related genes osteocalcin, sclerostin and cathepsin $\mathrm{K}$, and calcitonin (Table 1). The primary transcript of chicken calcitonin/CGRP gene (Gene ID: 396256) is alternatively spliced into exons 1, 2, 3 and 4 for calcitonin, and exons $1,2,3,5$ and 6 for CGRP. PCR primers for calcitonin were designed in exon 4 , and the primer sequences were designed to not cross CGRP. PCR amplifications were performed using an Mx3000P qPCR System (Agilent Technologies) and SYBR Ex Taq DNA Polymerase (Takara Bio). The conditions for real-time RT-PCR consisted of 40 cycles of denaturation at $95^{\circ} \mathrm{C}$ for $10 \mathrm{~s}$ and annealing/extension at $60^{\circ} \mathrm{C}$ for $40 \mathrm{~s}$, followed by melt curve analysis. The mRNA expression level of each gene of interest was normalised to that of GAPDH, as an internal standard. There were no changes and/or trends in GAPDH mRNA expression levels among embryonic ages. The correlations among melatonin receptors, bone-related genes and calcitonin mRNA expression levels were determined from these data. The number of samples used for the correlation analyses was 32 in total, including E14 $(n=6), \mathrm{E} 16(n=10), \mathrm{E} 18(n=8)$ and $\mathrm{E} 20(n=8)$.

In addition, histological analysis was performed with alkaline phosphatase (for osteoblasts; Burston's azo-dye method), tartrate-resistant acid phosphatase (for osteoclasts; Cole's azo-dye method) and methyl green (for nuclei) staining in E14 and E16 chick embryo calvariae.

\section{In ovo injection of melatonin}

To examine the action of melatonin on bone tissue, in ovo injection was performed. Melatonin (5, 50 and $500 \mu \mathrm{g}$; Wako Pure Chemical Industries, Osaka, Japan) or a vehicle (saline with 5\% dimethyl sulfoxide) was repeatedly injected into the air cells of inseminated eggs at E15 and E16. Calvariae without the periosteum were sampled at E17, and the mRNA expression levels of functional factors of osteoblast (osteocalcin and ALP), osteocyte (sclerostin, dentin matrix protein 1; DMP1 and matrix extracellular phosphoglycoprotein; MEPE) and osteoclast (cathepsin $\mathrm{K}$ and matrix metalloproteinase 9; MMP9), as well as RANKL, OPG and calcitonin were measured by real-time RT-PCR. The PCR conditions were the same as those described above and the primer sequences are listed in Table 1. There were no changes and/or trends in the mRNA expression levels of GAPDH, an internal standard, among melatonin-treated groups vs control.

\section{In vitro melatonin treatment}

In order to investigate the direct action of melatonin on bone tissue, the calvariae of newly hatched chicks were cultured in vitro. Briefly, the calvariae of newly 
hatched chicks without the periosteum were collected and cut midsagittally and then divided into control and experimental groups. The obtained hemi-calvariae were washed three times with phosphate-buffered saline and pre-cultured in $500 \mu \mathrm{L}$ of BGJb medium (Thermo Fisher Scientific) supplemented with $0.1 \%$ bovine serum albumin for $24 \mathrm{~h}$ at $37^{\circ} \mathrm{C}$ under an atmosphere of $5 \% \mathrm{CO}_{2} / 95 \%$ air. After pre-culturing, the medium was replaced with fresh medium with or without the addition of melatonin (final concentration, $10^{-7} \mathrm{M}$ or $10^{-5} \mathrm{M}$ with $0.1 \%$ ethanol) followed by $72 \mathrm{~h}$ of culture. Thereafter, the cultured hemicalvariae were salvaged and the mRNA expression levels of cathepsin K, MMP9 and calcitonin were determined by real-time RT-PCR in a similar manner. The cultured medium was also collected and stored at $-80^{\circ} \mathrm{C}$ until assayed for calcitonin concentrations using a chicken calcitonin enzyme-linked immunosorbent assay (ELISA) kit (LifeSpan BioSciences, Seattle, WA, USA) in accordance with the manufacturer's instructions.

\section{Immunohistochemical analysis of melatonin receptors and calcitonin in chick calvariae}

For immunohistochemical analyses, calvariae of E20 embryos and newly hatched chicks without the periosteum were fixed in $4 \%$ paraformaldehyde in $0.1 \mathrm{M}$ phosphate buffer ( $\mathrm{pH}$ 7.4) and modestly decalcified with 5\% EDTA ( $\mathrm{pH} 7.4)$. For immunostaining of the melatonin receptors, calvariae were dehydrated in a graded series of ethanol, cleared with xylene, embedded in paraffin and sectioned at $5 \mu \mathrm{m}$. Cryosections of the calvariae, at a thickness of $5 \mu \mathrm{m}$, were used for calcitonin immunostaining. Antigen retrieval was performed by heating the specimens in citrate buffer solution (pH 6.0), followed by incubation at $4^{\circ} \mathrm{C}$ overnight with rabbit anti-human MT2 antibody (dilution, 1:500; Medical and Biological Laboratories, Nagoya, Japan) or rabbit anti-salmon calcitonin antibody (1:50,000; Okuda et al. 1999) as a primary antibody, respectively. For the calcitonin antibody, due to the amino acid sequence high similarity (84.4\%) between salmon and chicken calcitonin, this antibody is able to crossreact with chicken calcitonin. Antibodies pre-absorbed with each antigenic peptide were used as a negative control. Immunopositive reactions were enhanced with the VECTASTAIN Elite ABC-Peroxidase Kit (Vector Laboratories, Burlingame, CA, USA) and visualised with 3,3'-diaminobenzidine. Finally, the slides were counterstained with methyl green or haematoxylin. The images were gained by microscopy observations, and only minor adjustments in their brightness and contrast were made.

\section{Statistical analysis}

Data are presented as the mean \pm standard error of the mean. Statistical analyses were performed using one-way analysis of variance followed by the Tukey-Kramer test or the paired $t$-test. A probability $(P)$ value of $<0.05$ was considered statistically significant.

\section{Results}

mRNA expression levels of melatonin receptors and bone-related genes in chick calvariae during embryonic development

The mRNA expression patterns of the melatonin receptors (mel1a, mel1b and mel1c) were analysed by RT-PCR and agarose gel electrophoresis. As a result, mel1a and mel1c mRNA were detected in the calvariae of E20 chick embryos, while mel1b and mel1c were observed in the cerebrum (Fig. 1A). During embryonic development, mel1a and mel1c were markedly elevated in the calvariae from E16 onward (>500 and 470\% vs E14, respectively) (Fig. 1B and $\mathrm{C}$ ). For bone-related genes, the mRNA expression level of osteocalcin (a marker of osteoblast) was gradually increased during development (Fig. 1D) and that of sclerostin (a marker of osteocyte) was highly expressed from E16 ( $>450 \%$ vs E14), as was the melatonin receptors (Fig. 1E), whereas there was no significant change in mRNA expression of cathepsin $\mathrm{K}$ (a marker of osteoclast) (Fig. 1F). The data with individual values are shown in Supplementary Fig. 1 (see section on supplementary data given at the end of this article). In addition, histological analysis with triple-staining of E14 and E16 chick calvariae demonstrated a clear increase in the number of osteocytes in E16 compared with E14. Meanwhile, a small number of osteoclasts were observed, but the count did not appear to be different between E14 and E16 (Supplementary Fig. 2).

\section{Effects of in ovo injection of melatonin on the expression of bone-related genes in chick calvariae}

Repeated in ovo injection of melatonin $(5,50$ and $500 \mu \mathrm{g}$ ) into the air cells of inseminated eggs at E15 and E16 did not affect mRNA expression of osteocalcin and ALP (functional factors of osteoblast) in the calvariae (Fig. 2A and $\mathrm{B}$ ); however, the mRNA expression levels of sclerostin, DMP1 and MEPE (functional factors of 
A
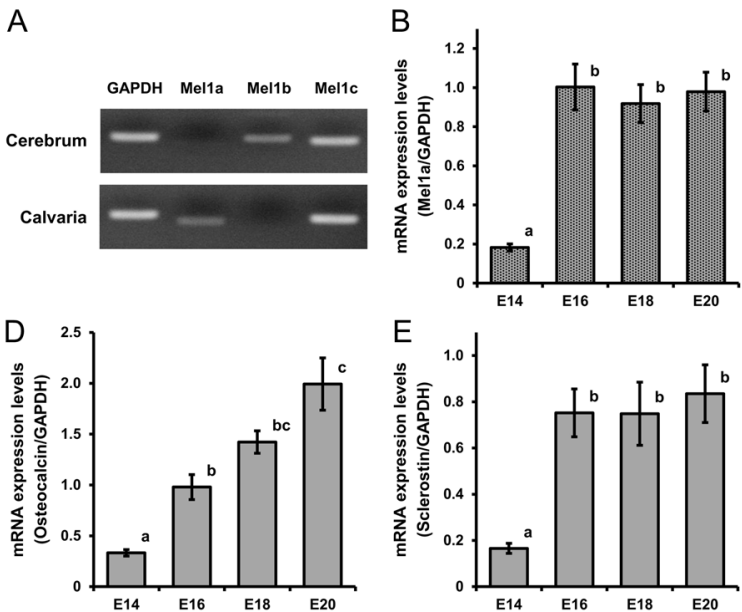

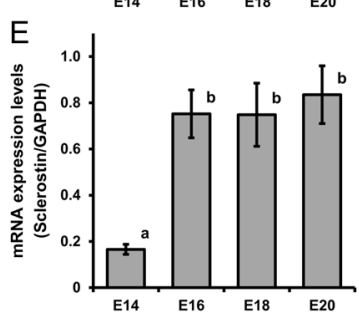

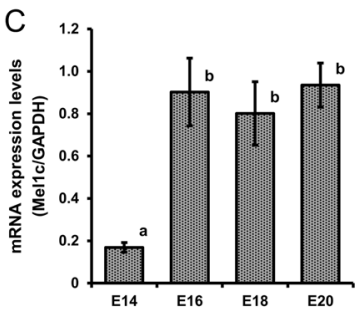

F

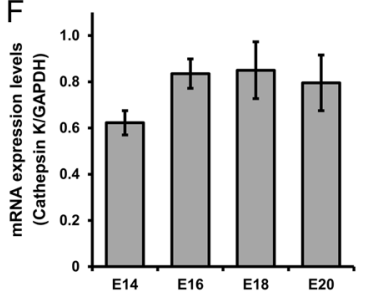

Figure 1

Changes in the mRNA expression levels of melatonin receptors and bone-related genes in chick calvariae during embryonic development. (A) mRNA expression patterns of melatonin receptors in the cerebrum and calvariae of E20 embryos. mRNA expression levels of the melatonin receptors (B) mel1a and (C) mel1c, and the bone-related genes (D) osteocalcin, (E) sclerostin and (F) cathepsin K in E14, 16, 18 and 20 embryo calvariae. Relative mRNA expression levels were determined by real-time RT-PCR and normalised to GAPDH mRNA levels. Columns with different letters indicate significant differences $(P<0.05$; Tukey-Kramer test, $n=6-10)$. osteocyte) (68.2-43.8\%, 90.5-59.8\% and 82.6-64.0\%, respectively), as well as cathepsin $\mathrm{K}$ and MMP9 (functional factors of osteoclast) (86.1-59.2\% and 87.9-59.6\%, respectively) were dose-dependently decreased (Fig. 2C, D, E, F and G). Meanwhile, there were no significant changes in the mRNA expression levels of RANKL and OPG (Fig. $2 \mathrm{H}$ and I). The data with individual values are shown in Supplementary Fig. 3.

\section{Expression analysis of melatonin receptors in chick osteocytes}

The mRNA expression levels of the melatonin receptors mel1a and mel1c were weakly, but positively, correlated with that of osteocalcin ( $r=0.396$ and 0.255 , respectively) (Fig. 3A and B), while strong positive correlations were observed with sclerostin mRNA expression $(r=0.822$ and 0.870) (Fig. 3C and D). However, there were no correlations between the mRNA expression levels of the melatonin receptors and cathepsin $\mathrm{K}(r=-0.045$ and -0.043$)$ (Fig. 3E and F). The number of samples used for the correlation analyses was 32 in total, including E14 $(n=6)$, E16 $(n=10)$, E18 $(n=8)$ and E20 $(n=8)$. Immunohistochemical analysis of calvariae showed immunopositive reactions for the melatonin receptors principally in osteocytes trapped in the bone matrix (Fig. 3G), while only slightly in osteoclasts (data not shown). These reactions were abolished with the use of peptide pre-absorbed primary antibody (Fig. 3H).

\section{Expression of calcitonin in chick calvariae}

The mRNA expression of calcitonin, an ultimobranchial gland hormone that suppresses osteoclastic activity, was noticed in chick embryo calvariae and the mRNA expression levels were elevated from E16 (>590\% vs E14,
Fig. 4A and Supplementary Fig. 1F), as with those of the melatonin receptors and sclerostin (Fig. 1B, C and E). Meanwhile, the mRNA expression level of calcitonin was poorly, but positively, correlated with that of osteocalcin $(r=0.313)$ (Fig. 4B), whereas a marked positive correlation was found with sclerostin mRNA expression $(r=0.896)$ (Fig. 4C). However, there was no correlation between calcitonin and cathepsin $\mathrm{K}$ mRNA expression levels $(r=-0.074)$ (Fig. 4D). Immunohistochemical analysis revealed the calcitonin expression in buried osteocytes and the cells on the surface of calvariae, which were thought to be osteoblast-lineage cells, either osteoblasts or bone lining cells (osteoblasts in a resting state) (Fig. 4E). The immunopositive reactions were dissipated when using the peptide pre-absorbed primary antibody (Fig. 4F).

\section{Effects of melatonin treatment on calcitonin expression in chick calvariae and secretion of calcitonin in cultured medium}

Repeated in ovo injection of melatonin (5, 50 and 500 $\mu \mathrm{g}$ ) into the air cells of inseminated eggs significantly raised calcitonin mRNA expression levels in calvariae (112.7140.0\%) (Fig. 5A and Supplementary Fig. 3J). After 3 days of in vitro melatonin treatment $\left(10^{-7} \mathrm{M}\right.$ and $10^{-5} \mathrm{M}$ final conc.) of newly hatched chick calvariae, both calcitonin mRNA expression levels in calvariae (126.3-143.4\%) and concentrations of calcitonin in the cultured medium (251.2-385.7\%) were augmented in a dose-dependent manner (Fig. 5B and C). Besides in ovo injection, the mRNA expression levels of cathepsin K and MMP9 were significantly decreased (76.6-69.1\% and 78.5-73.7\%, respectively) in the organ culture system (Fig. 5D and $\mathrm{E})$. The data with individual values are shown in Supplementary Fig. 4. 
A
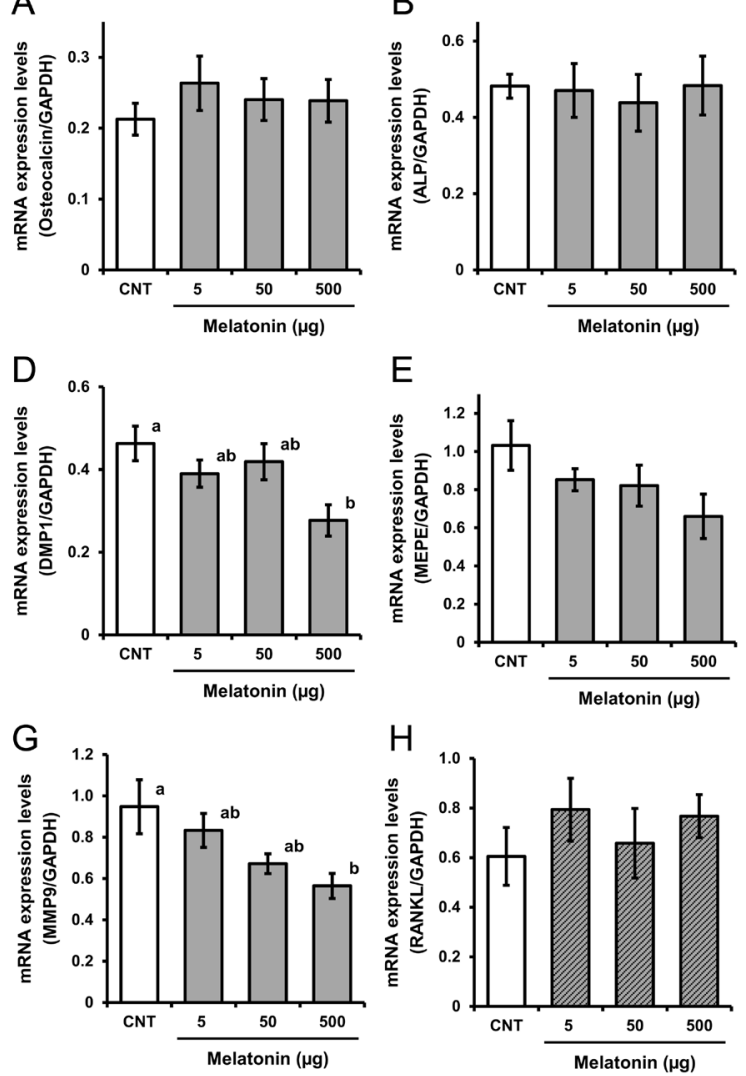

In addition, calcitonin mRNA expression levels in chick embryo calvariae demonstrated intense positive correlations with melatonin receptor mRNA levels $(r=0.881$ vs mella and 0.966 vs mel1c) (Fig. $6 \mathrm{~A}$ and B). A summarised image of the osteoclast suppressive effect of melatonin via osteocyte function is shown in Fig. 6C.

\section{Discussion}

Cell-to-cell interactions among osteoblasts, osteoclasts and osteocytes are thought to be very important for adequate bone modelling and remodelling. Thus, isolated and cultured cells may not be suitable to investigate the actual physiological activities and functions. In this respect, chick calvariae, which are composed of osteoblasts, osteocytes and osteoclasts with relatively low amounts of bone marrow, could be a good model system. In addition, an in ovo experiment system, which is scarcely influenced by ambient light conditions, is better suited to evaluate the in vivo effect of exogenous melatonin administration on bone formation. The use of chick calvariae as a model of bone demonstrated the expression of the melatonin receptors and calcitonin expression of osteocytes for the first time and suggests a new mechanism underlying the suppressive effect of melatonin on osteoclasts via upregulation of calcitonin secretion by osteocytes (Fig. 6C).

The involvement of melatonin function in bone modelling and turnover seems to be conserved evolutionarily in vertebrates. In fishes and birds, pinealectomy causes spinal malformations with a reduction in vertebral mineral content (Fjelldal et al. 2004, Turgut et al. 2005). Likewise, patients with adolescent idiopathic scoliosis (AIS) have either low levels of circulating melatonin or impaired melatonin signalling (Sadat-Ali et al. 2000, Moreau et al. 2004, Azeddine et al. 2007, Man et al. 2011), which are often accompanied with juvenile osteoporosis (Burner et al. 1982, Cheng et al. 2000). Previously, we demonstrated a suppressive effect of melatonin on the activity of osteoclasts using fish scales as a bone model (Suzuki \& Hattori 2002), and this observation was consistent with in vivo studies in mice (Koyama et al. 2002, Histing et al. 2012) and humans (Kotlarczyk et al. 2012, Amstrup et al. 2015). The results of the present study also showed an osteoclast suppressive effect of melatonin both in ovo and in vitro using chick calvariae. 
A Mel1a vs. Osteocalcin

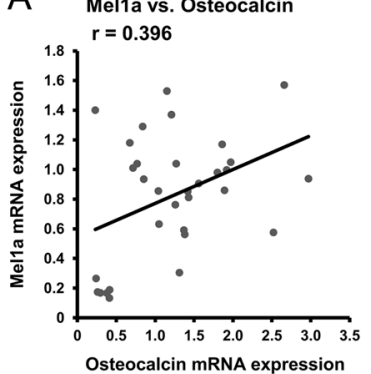

B Mel1c vs. Osteocalcin

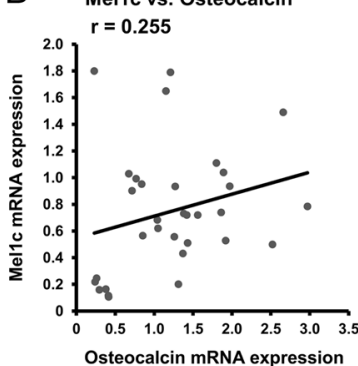

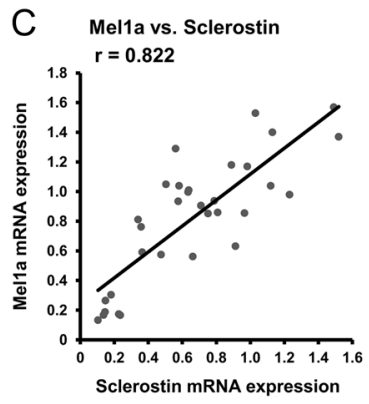

D Mel1c vs. Sclerostin

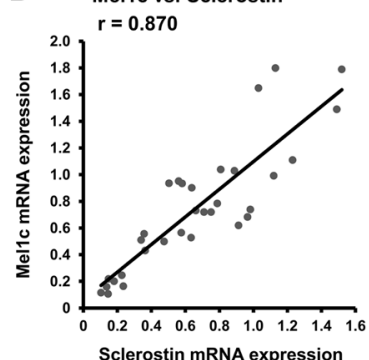

E

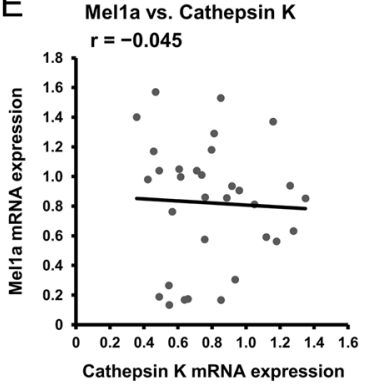

$\mathrm{F}$

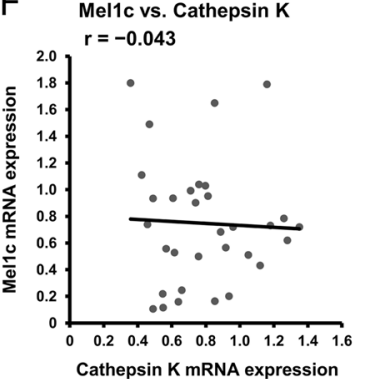

G

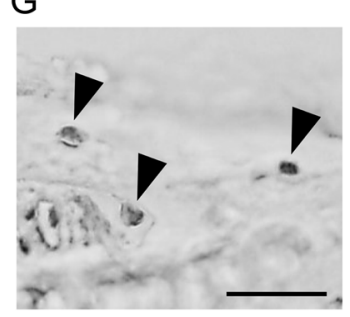

$\mathrm{H}$

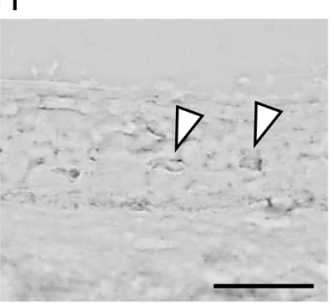

\section{Figure 3}

Expression of melatonin receptors in chick osteocytes. Correlation coefficients between melatonin receptors (mel1a and mel1 $\mathrm{c}$ ) and the bone-related genes ( $A$ and $B$ ) osteocalcin, ( $C$ and $D$ ) sclerostin and ( $E$ and $F$ ) cathepsin $K$ were determined from the mRNA expression levels in chick embryo calvariae $(n=32)$. Immunohistochemical staining of E20 embryo calvariae was performed using (G) anti-MT2 melatonin receptor antibody or (H) pre-absorbed antibody. Black and white arrowheads indicate osteocytes with immunopositive and -negative reactions, respectively (bars $=20 \mu \mathrm{m})$.

Also, we confirmed the expression of calcitonin and melatonin receptor (MT2) in human bone tissue, as well as chick calvariae in the present study, and found strong positive correlations among mRNA expression levels of human calcitonin, MT2 melatonin receptor and sclerostin, a marker of osteocyte (Nakano M, Ikegame M, Yamamoto T \& Hattori A, unpublished observations). Moreover, we found that melatonin treatment increased calcitonin secretion in cultured rat calvariae and fish scales, which is homologous to a membrane bone (Ikegame M, Hattori A \& Suzuki N, unpublished observations). Therefore, we concluded that melatonin could suppress osteoclastic activity via upregulation of calcitonin secretion by osteocytes, not only in chickens, but in other vertebrate species including humans.

In lower vertebrates, including chickens, three membrane receptors for melatonin, termed mel1a, mel1b and mel1c, have been identified. RT-PCR analysis revealed
A

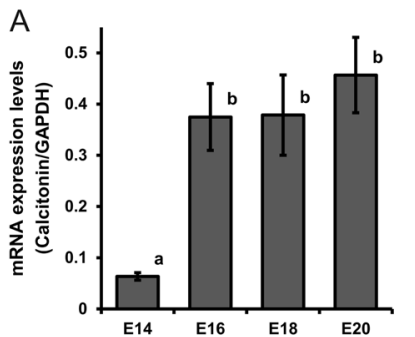

B

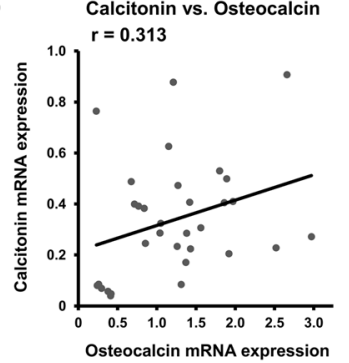

E
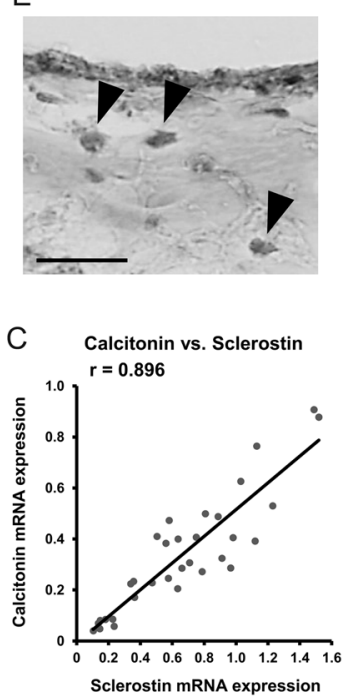

F
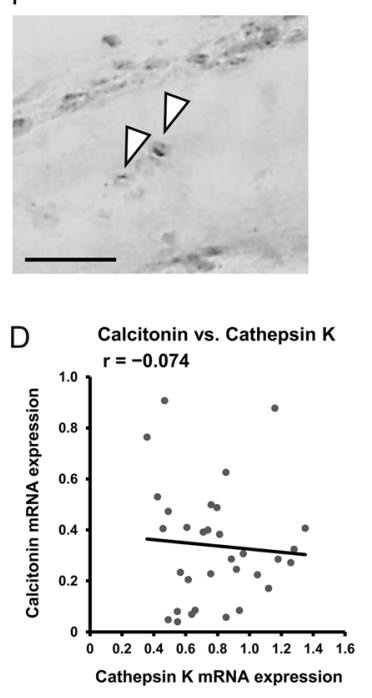

Figure 4

Expression of calcitonin in chick calvariae. (A) mRNA expression levels of calcitonin in chick calvariae during embryonic development. Columns with different letters indicate significant differences ( $P<0.05$; Tukey-Kramer test, $n=6-10)$. Correlation coefficients between calcitonin and the bone-related genes (B) osteocalcin, (C) sclerostin and (D) cathepsin $\mathrm{K}$ were determined from the mRNA expression levels in chick embryo calvariae $(n=32)$. Immunohistochemical staining of newly hatched chick calvariae was performed using (E) anti-calcitonin antibody or (F) preabsorbed antibody. Black and white arrowheads indicate osteocytes with immunopositive and -negative reactions, respectively (bars $=20 \mu \mathrm{m}$ ). 

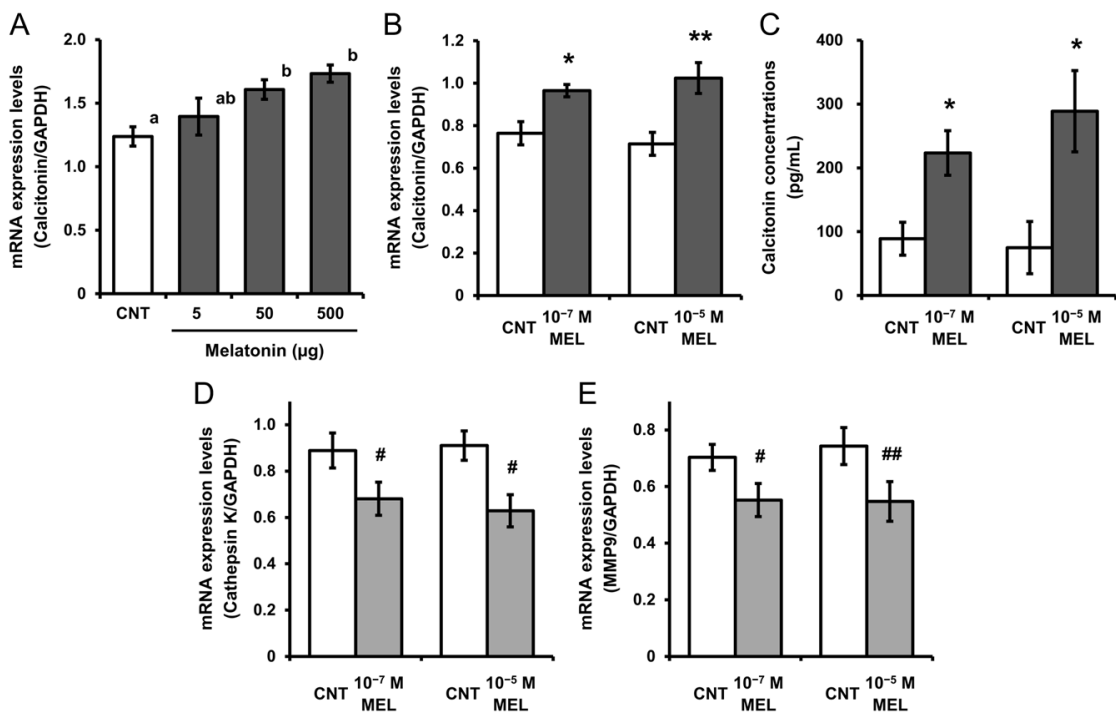

\section{Figure 5}

Effects of in ovo and in vitro treatment of melatonin on calcitonin expression in chick calvariae. (A) mRNA expression levels of calcitonin were measured in E17 embryo calvariae after in ovo injection of melatonin. Columns with different letters indicate significant differences $(P<0.05$; Tukey-Kramer test, $n=6-8$ ). (B) mRNA expression levels of calcitonin and (C) concentrations of calcitonin in the medium were measured in newly hatched chick calvariae after 3 days of incubation with or without melatonin (10-7 $\mathrm{M}$ and $\left.10^{-5} \mathrm{M}\right)$ by real-time RT-PCR and specific ELISA kits, respectively $(n=5-8)$. mRNA expression levels of the functional factors of osteoclasts, (D) cathepsin $\mathrm{K}$ and (E) MMP9, in newly hatched chick calvariae were also measured after 3 days of incubation. $\star P<0.05, * * P<0.01, \# P<0.05$ and $\# P<0.01$ vs the control group (paired $t$-test). the mRNA expression profiles of mel1a and mel1c in chick calvariae, while those of mel1b and mel1c were observed in the cerebrum. The expression patterns of melatonin receptors in the cerebrum were in agreement with previous reports (Liu et al. 1995, Reppert et al. 1995). To date, melatonin receptor expression in osteoblasts has been demonstrated in mammals, including humans (Satomura et al. 2007, Man et al. 2011). However, in this study, the mRNA expression levels of the melatonin receptors mel1a and mel1c were much more strongly and positively correlated with sclerostin mRNA expression than that of osteocalcin. Furthermore, immunopositive reactions of the melatonin receptors were detected in matured osteocytes buried in the bone matrix, rather than osteoblasts or bone lining cells on the surface of chick calvariae.
Although previous studies have shown that melatonin promotes osteoblast differentiation and enhances the functional activities of several cell lines and isolated primary osteoblasts (Roth et al. 1999, Radio et al. 2006, Satomura et al. 2007, Zhang et al. 2010, Park et al. 2011), we found that melatonin had no influence by in ovo injection on osteocalcin and ALP mRNA expression levels in chick embryo calvariae. This observation of osteoblastic activity is consistent with in vivo melatonin injection in mice (Koyama et al. 2002) and oral administration in rats (Ladizesky et al. 2003) or our former data from an in vitro culture system using fish scales, in which osteoblasts and osteoclasts co-existed (Suzuki \& Hattori 2002). These findings may imply differences of melatonin action on osteoblasts between solely cultured and those co-existing with osteoclasts,

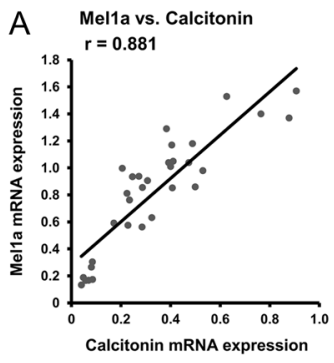

B Mel1c vs. Calcitonin

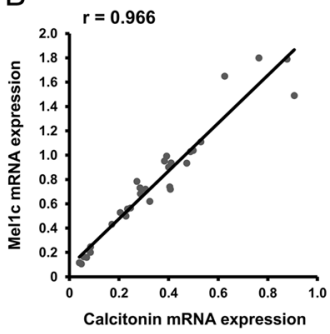

C Immature Osteocyte (Sclerostin level low)

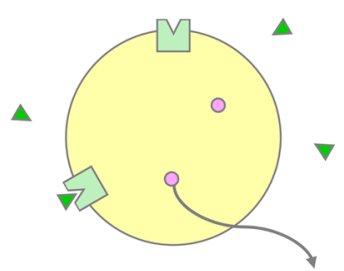

\section{$\Delta$}

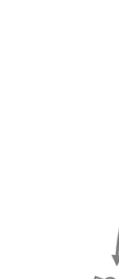

(c) 2019 Society for Endocrinology Published by Bioscientifica Ltd. Printed in Great Britain

Mature Osteocyte (Sclerostin level high)

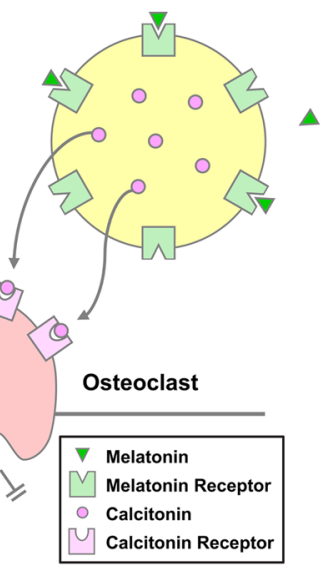

\section{Figure 6}

A possible mechanism for the osteoclast suppressive effect of melatonin via osteocyte secretion of calcitonin. (A and B) Correlation coefficients between melatonin receptors (mel1a and mel1c) and calcitonin were also calculated on the basis of mRNA expression levels in chick embryo calvariae $(n=32)$. (C) A summarised image of the osteoclast-suppressive effect of melatonin by osteocyte secretion of calcitonin. A full colour version of this figure is available at https://doi. org/10.1530/JOE-18-0707. 
thereby reflecting physiological conditions. On the other hand, in ovo injection of melatonin decreased the mRNA expression levels of sclerostin, as well as DMP1 and MEPE in chick calvariae. To the best of our knowledge, this observation is the first to give the influence of melatonin on the expression of osteocyte marker genes. However, the mechanisms of melatonin action on osteocyte marker genes expression are unclear. Therefore, further studies to precisely investigate the effects of melatonin on osteocyte activities are required. Moreover, both in ovo and in vitro treatment of melatonin suppressed the functional activities of osteoclasts in a dose-dependent manner. Some functional factors of osteoclast such as cathepsin $\mathrm{K}$ and MMP9 are also expressed by osteocytes and are thought to be involved in osteocytic osteolysis. However, since there was no correlation between mRNA expression levels of cathepsin $\mathrm{K}$ and sclerostin, an osteocyte marker $(r=0.053)$, we inferred that these factors were expressed principally by osteoclasts rather than osteocytes, at least in our study conditions. This suppressive effect of melatonin on osteoclastic activity is in agreement with previous reports (Koyama et al. 2002, Suzuki \& Hattori 2002, Histing et al. 2012). However, unexpectedly, no significant changes in RANKL and OPG mRNA expression levels were found in chick embryo calvariae, despite the decrease in sclerostin expression. Instead, both calcitonin mRNA expression in calvariae and concentrations of calcitonin in cultured medium were dose-dependently increased by in ovo and in vitro melatonin treatment.

Calcitonin, an osteoclast-suppressing hormone, is primarily secreted by $\mathrm{C}$ cells of the thyroid gland in mammals or the ultimobranchial gland in lower vertebrates, including chickens. To date, calcitonin production has been validated in brain, pituitary, liver, lung and kidney of mammals including humans (Deftos et al. 1980, Flynn et al. 1981, Russwurm et al. 2001), and also in the brain and pituitary gland of avian species (Galan Galan et al. 1981, Maddineni et al. 2007). In the present study, we found the calcitonin mRNA expression in chick calvariae and immunohistochemical analysis revealed the calcitonin expression in osteocytes and bone lining cells of chick calvariae. To the best of our knowledge, this is the first report to demonstrate calcitonin expression in bone tissue. Melatonin receptor expression by osteocytes together with the marked positive correlations of mRNA expression levels among sclerostin (a marker of osteocyte), melatonin receptors and calcitonin (Figs 3C, D, 4C and $6 \mathrm{~A}, \mathrm{~B})$ strongly suggests that melatonin affects osteocytes directly and suppresses osteoclastic activity via upregulation of calcitonin secretion by osteocytes (Fig. 6C).
Gooi et al. (2010) reported calcitonin receptor expression in rat calvariae osteocytes, as well as significant upregulation of sclerostin expression in osteocytes by calcitonin treatment. Secretion of calcitonin by osteocytes, as noted in our study, suggested that calcitonin may affect other osteocytes in a paracrine manner. However, expression of calcitonin receptor by osteocytes has not been identified in birds, including chickens. In the present study, melatonin treatment led to the downregulation of sclerostin expression concomitant with increased calcitonin expression. If calcitonin secreted by osteocytes in chick calvariae affected other osteocytes in a paracrine fashion, the results of the present study would conflict with those reported by Gooi et al. Therefore, it is worth studying calcitonin receptor expression in osteocytes and the paracrine action of calcitonin secreted by osteocytes in other vertebrate species including chickens.

Pinealectomy of newly hatched chicks causes scoliosis, which can be restored by pineal body autograft (Machida et al. 1993) or melatonin administration (Katoh $\&$ Hattori 1995, Kono et al. 2011). These findings point out the importance of melatonin signalling for appropriate bone development and modelling. The experimental induction of scoliosis by pinealectomy of newly hatched chick is often associated with osteoporosis, which is characterised by lowered bone mineral density (Turgut et al. 2005, Kono et al. 2011, Aota et al. 2013). As with the experimental chick model, the prevalence of juvenile osteoporosis has also been reported in AIS patients (Burner et al. 1982, Cheng et al. 2000). The pathological conditions of spinal deformity and osteoporosis might be due to an imbalance between bone formation and resorption. In the vertebrae of the chicken experimental scoliosis model, the abundance of activated osteoclasts was increased (Yoshihara et al. 2005, Aota et al. 2013), while the numbers of osteoblasts (Kono et al. 2011) and osteocytes (Turgut et al. 2005) were reduced. These factors are thought to contribute to the development of scoliotic and osteoporotic states. The results of the present study showed that melatonin treatment upregulated calcitonin secretion in chick calvariae. We therefore consider that decreased level of calcitonin, which is locally secreted by osteocytes, caused by a deficiency of melatonin signalling is an etiological factor of spinal deformity and osteoporosis in pinealectomised chickens.

So far, studies have investigated the possible effects of melatonin on the treatment of osteoporosis. Even though modest and limited effects have been reported, melatonin was found to enhance the potency of estradiol in the prevention of bone loss in rats caused by ovariectomy 
(Ladizesky et al. 2001, 2003). Moreover, we also found significant increases in bone mineral density and bone strength in aged male mice following administration of melatonin in drinking water (Igarashi-Migitaka J, Suzuki $\mathrm{N} \&$ Hattori A, unpublished observations). In addition, we recently developed a synthetic melatonin derivative, 1-benzyl-2,4,6-tribromomelatonin (bromomelatonin), and the oral administration of this agent augmented the total bone mineral density of the femoral metaphysis in both ovariectomised rats and those fed a low-calcium diet with more capability than melatonin (Suzuki et al. 2008a,b). More recently, the effects of melatonin treatment on human bone were examined in peri- and post-menopausal women. These studies demonstrated the beneficial effects of oral melatonin administration on bone health, as the imbalance of bone turnover and lowered bone mineral density were improved (Kotlarczyk et al. 2012, Amstrup et al. 2015). Nonetheless, further studies are required to determine whether the action of melatonin, which suppresses osteoclast function via upregulation of calcitonin secretion by osteocytes, is observed in both ovariectomised rats and peri- or postmenopausal women.

\section{Supplementary data}

This is linked to the online version of the paper at https://doi.org/10.1530/ JOE-18-0707.

\section{Declaration of interest}

The authors declare that there is no conflict of interest that could be perceived as prejudicing the impartiality of the research reported.

\section{Funding}

This work was supported by JSPS KAKENHI Grant Number JP18K11016, JP16K11442 and JP16K07871, and Grant-in-Aid for Scientific Research at Tokyo Medical and Dental University.

\section{Author contribution statement}

Study design: $\mathrm{A} \mathrm{H}$ and M N. Study conduct and data collection: $\mathrm{M} \mathrm{N}, \mathrm{M} \mathrm{I}, \mathrm{J}$ $M$ and $Y$ M. Data analysis: $M N$ and $M I$. Data interpretation: $A H, M N$ and $\mathrm{N}$ S. Drafting manuscript: $\mathrm{M} \mathrm{N}$ and $\mathrm{A} \mathrm{H}$. Approval of final version of the manuscript: all authors.

\section{References}

Amstrup AK, Sikjaer T, Mosekilde L \& Rejnmark L 2013 Melatonin and the skeleton. Osteoporosis International 24 2919-2927. (https://doi. org/10.1007/s00198-013-2404-8)

Amstrup AK, Sikjaer T, Heickendorff L, Mosekilde L \& Rejnmark L 2015 Melatonin improves bone mineral density at the femoral neck in postmenopausal women with osteopenia: a randomized controlled trial. Journal of Pineal Research 59 221-229. (https://doi.org/10.1111/ jpi.12252)

Aota Y, Terayama H, Saito T \& Itoh M 2013 Pinealectomy in a broiler chicken model impairs endochondral ossification and induces rapid cancellous bone loss. Spine Journal 13 1607-1616. (https://doi. org/10.1016/j.spinee.2013.05.017)

Azeddine B, Letellier K, Wang da S, Moldovan F \& Moreau A 2007 Molecular determinants of melatonin signaling dysfunction in adolescent idiopathic scoliosis. Clinical Orthopaedics and Related Research 462 45-52. (https://doi.org/10.1097/BLO.0b013e31811f39fa)

Burner WL, Badger VM \& Sherman FC 1982 Osteoporosis and acquired back deformities. Journal of Pediatric Orthopedics 2 383-385. (https:// doi.org/10.1097/01241398-198210000-00006)

Cardinali DP, Esquifino AI, Srinivasan V \& Pandi-Perumal SR 2008 Melatonin and the immune system in aging. Neuroimmunomodulation 15 272-278. (https://doi.org/10.1159/000156470)

Cheng JC, Qin L, Cheung CS, Sher AH, Lee KM, Ng SW \& Guo X 2000 Generalized low areal and volumetric bone mineral density in adolescent idiopathic scoliosis. Journal of Bone and Mineral Research 15 1587-1595. (https://doi.org/10.1359/jbmr.2000.15.8.1587)

Csaba G \& Baráth P 1974 The effect of pinealectomy on the parafollicular cells of the rat thyroid gland. Acta Anatomica 88 137-146. (https:// doi.org/10.1159/000144231)

Csaba G \& Baráth P 1975 Morphological changes of thymus and the thyroid gland after postnatal extirpation of pineal body. Endocrinologia Experimentalis 9 59-67.

Deftos LJ, Burton DW, Watkins WB \& Catherwood BD 1980 Immunohistological studies of artiodactyl and teleost pituitaries with antisera to calcitonin. General and Comparative Endocrinology 42 9-18. (https://doi.org/10.1016/0016-6480(80)90251-8)

Fjelldal PG, Grotmol S, Kryvi H, Gjerdet NR, Taranger GL, Hansen T, Porter MJ \& Totland GK 2004 Pinealectomy induces malformation of the spine and reduces the mechanical strength of the vertebrae in Atlantic salmon, Salmo salar. Journal of Pineal Research 36 132-139. (https://doi.org/10.1046/j.1600-079X.2003.00109.x)

Flynn JJ, Margules DL \& Cooper CW 1981 Presence of immunoreactive calcitonin in the hypothalamus and pituitary lobes of rats. Brain Research Bulletin 6 547-549. (https://doi.org/10.1016/S03619230(81)80030-5)

Franz-Odendaal TA, Hall BK \& Witten PE 2006 Buried alive: how osteoblasts become osteocytes. Developmental Dynamics 235 176-190. (https://doi.org/10.1002/dvdy.20603)

Galan Galan F, Rogers RM, Girgis SI \& MacIntyre I 1981 Immunoreactive calcitonin in the central nervous system of the pigeon. Brain Research 212 59-66. (https://doi.org/10.1016/0006-8993(81)90032-9)

Gooi JH, Pompolo S, Karsdal MA, Kulkarni NH, Kalajzic I, McAhren SH, Han B, Onyia JE, Ho PW, Gillespie MT, et al. 2010 Calcitonin impairs the anabolic effect of PTH in young rats and stimulates expression of sclerostin by osteocytes. Bone 46 1486-1497. (https://doi. org/10.1016/j.bone.2010.02.018)

Histing T, Anton C, Scheuer C, Garcia P, Holstein JH, Klein M, Matthys R, Pohlemann T \& Menger MD 2012 Melatonin impairs fracture healing by suppressing RANKL-mediated bone remodeling. Journal of Surgical Research 173 83-90. (https://doi.org/10.1016/j.jss.2010.08.036)

Katoh H \& Hattori A 1995 Experimental scoliosis produced by pinealectomy and characterization of melatonin binding sites in vertebrae of chicks. St. Marianna Medical Journal 23 853-861.

Knothe Tate ML, Adamson JR, Tami AE \& Bauer TW 2004 The osteocyte. International Journal of Biochemistry and Cell Biology 36 1-8. (https:// doi.org/10.1016/S1357-2725(03)00241-3)

Kono H, Machida M, Saito M, Nishiwaki Y, Kato H, Hosogane N, Chiba K, Miyamoto T, Matsumoto M \& Toyama Y 2011 Mechanism of osteoporosis in adolescent idiopathic scoliosis: experimental scoliosis in pinealectomized chickens. Journal of Pineal Research 51 387-393. (https://doi.org/10.1111/j.1600-079X.2011.00901.x) https://joe.bioscientifica.com https://doi.org/10.1530/JOE-18-0707 (c) 2019 Society for Endocrinology Published by Bioscientifica Ltd. Printed in Great Britain 
Kotlarczyk MP, Lassila HC, O’Neil CK, D'Amico F, Enderby LT, Witt-Enderby PA \& Balk JL 2012 Melatonin osteoporosis prevention study (MOPS): a randomized, double-blind, placebo-controlled study examining the effects of melatonin on bone health and quality of life in perimenopausal women. Journal of Pineal Research 52 414-426. (https://doi.org/10.1111/j.1600-079X.2011.00956.x)

Koyama H, Nakade O, Takada Y, Kaku T \& Lau KH 2002 Melatonin at pharmacologic doses increases bone mass by suppressing resorption through down-regulation of the RANKL-mediated osteoclast formation and activation. Journal of Bone and Mineral Research $\mathbf{1 7}$ 1219-1229. (https://doi.org/10.1359/jbmr.2002.17.7.1219)

Kumar Jha P, Challet E \& Kalsbeek A 2015 Circadian rhythms in glucose and lipid metabolism in nocturnal and diurnal mammals. Molecular and Cellular Endocrinology 418 74-88. (https://doi.org/10.1016/j. mce.2015.01.024)

Ladizesky MG, Boggio V, Albornoz LE, Castrillón PO, Mautalen C \& Cardinali DP 2003 Melatonin increases oestradiol-induced bone formation in ovariectomized rats. Journal of Pineal Research $\mathbf{3 4}$ 143-151. (https://doi.org/10.1034/j.1600-079X.2003.00021.x)

Ladizesky MG, Cutrera RA, Boggio V, Somoza J, Centrella JM, Mautalen C \& Cardinali DP 2001 Effect of melatonin on bone metabolism in ovariectomized rats. Life Sciences 70 557-565. (https://doi. org/10.1016/S0024-3205(01)01431-X)

Liu F, Yuan H, Sugamori KS, Hamadanizadeh A, Lee FJ, Pang SF, Brown GM, Pristupa ZB \& Niznik HB 1995 Molecular and functional characterization of a partial cDNA encoding a novel chicken brain melatonin receptor. FEBS Letters 374 273-278. (https://doi. org/10.1016/0014-5793(95)01129-3)

Machida M, Dubousset J, Imamura Y, Iwaya T, Yamada T \& Kimura J 1993 An experimental study in chickens for the pathogenesis of idiopathic scoliosis. Spine 18 1609-1615. (https://doi.org/10.1097/00007632199309000-00007)

Machida M, Murai I, Miyashita Y, Dubousset J, Yamada T \& Kimura J 1999 Pathogenesis of idiopathic scoliosis. Experimental study in rats. Spine 24 1985-1989. (https://doi.org/10.1097/00007632-19991001000004)

Maddineni SR, Krzysik-Walker SM, Ocón-Grove OM, Motch SM, Hendricks GL 3rd \& Ramachandran R 2007 Calcitonin is expressed in the chicken pituitary gland: influence of gonadal steroids and sexual maturation. Cell and Tissue Research 327 521-528. (https://doi. org/10.1007/s00441-006-0331-0)

Man GC, Wong JH, Wang WW, Sun GQ, Yeung BH, Ng TB, Lee SK, Ng BK, Qiu Y \& Cheng JC 2011 Abnormal melatonin receptor 1B expression in osteoblasts from girls with adolescent idiopathic scoliosis. Journal of Pineal Research 50 395-402. (https://doi.org/10.1111/j.1600079X.2011.00857.x)

Moreau A, Wang DS, Forget S, Azeddine B, Angeloni D, Fraschini F, Labelle H, Poitras B, Rivard CH \& Grimard G 2004 Melatonin signaling dysfunction in adolescent idiopathic scoliosis. Spine $\mathbf{2 9}$ 1772-1781. (https://doi.org/10.1097/01.BRS.0000134567.52303.1A)

Okuda R, Sasayama Y, Suzuki N, Kambegawa A \& Srivastav AK 1999 Calcitonin cells in the intestine of goldfish and a comparison of the number of cells among saline-fed, soup-fed, or high Ca soup-fed fishes. General and Comparative Endocrinology 113 267-273. (https:// doi.org/10.1006/gcen.1998.7195)

Park KH, Kang JW, Lee EM, Kim JS, Rhee YH, Kim M, Jeong SJ, Park YG \& Kim SH 2011 Melatonin promotes osteoblastic differentiation through the BMP/ERK/Wnt signaling pathways. Journal of Pineal Research $\mathbf{5 1}$ 187-194. (https://doi.org/10.1111/j.1600-079X.2011.00875.x)

Radio NM, Doctor JS \& Witt-Enderby PA 2006 Melatonin enhances alkaline phosphatase activity in differentiating human adult mesenchymal stem cells grown in osteogenic medium via MT2 melatonin receptors and the MEK/ERK (1/2) signaling cascade. Journal of Pineal Research 40 332-342. (https://doi.org/10.1111/j.1600079X.2006.00318.x)

Reiter RJ 1991 Melatonin: the chemical expression of darkness. Molecular and Cellular Endocrinology 79 C153-C158. (https://doi. org/10.1016/0303-7207(91)90087-9)

Reiter RJ 1993 The melatonin rhythm: both a clock and a calendar. Experientia 49 654-664. (https://doi.org/10.1007/BF01923947)

Reppert SM, Weaver DR, Cassone VM, Godson C \& Kolakowski LF 1995 Melatonin receptors are for the birds: molecular analysis of two receptor subtypes differentially expressed in chick brain. Neuron $\mathbf{1 5}$ 1003-1015. (https://doi.org/10.1016/0896-6273(95)90090-X)

Roth JA, Kim BG, Lin WL \& Cho MI 1999 Melatonin promotes osteoblast differentiation and bone formation. Journal of Biological Chemistry $\mathbf{2 7 4}$ 22041-22047. (https://doi.org/10.1074/jbc.274.31.22041)

Russwurm S, Stonans I, Stonane E, Wiederhold M, Luber A, Zipfel PF, Deigner HP \& Reinhart K 2001 Procalcitonin and CGRP-1 mRNA expression in various human tissues. Shock 16 109-112. (https://doi. org/10.1097/00024382-200116020-00004)

Sadat-Ali M, al-Habdan I \& al-Othman A 2000 Adolescent idiopathic scoliosis. Is low melatonin a cause? Joint Bone Spine 67 62-64.

Satomura K, Tobiume S, Tokuyama R, Yamasaki Y, Kudoh K, Maeda E \& Nagayama M 2007 Melatonin at pharmacological doses enhances human osteoblastic differentiation in vitro and promotes mouse cortical bone formation in vivo. Journal of Pineal Research 42 231-239. (https://doi.org/10.1111/j.1600-079X.2006.00410.x)

Sharan K, Lewis K, Furukawa T \& Yadav VK 2017 Regulation of bone mass through pineal-derived melatonin-MT2 receptor pathway. Journal of Pineal Research 63. (https://doi.org/10.1111/jpi.12423)

Srinivasan V, Ohta Y, Espino J, Pariente JA, Rodriguez AB, Mohamed M \& Zakaria R 2013 Metabolic syndrome, its pathophysiology and the role of melatonin. Recent Patents on Endocrine, Metabolic and Immune Drug Discovery 7 11-25. (https://doi.org/10.2174/187221413804660953)

Suzuki N \& Hattori A 2002 Melatonin suppresses osteoclastic and osteoblastic activities in the scales of goldfish. Journal of Pineal Research 33 253-258. (https://doi.org/10.1034/j.1600-079X.2002.02953.x)

Suzuki N, Somei M, Kitamura K, Reiter RJ \& Hattori A $2008 a$ Novel bromomelatonin derivatives suppress osteoclastic activity and increase osteoblastic activity: implications for the treatment of bone diseases. Journal of Pineal Research 44 326-334. (https://doi. org/10.1111/j.1600-079X.2007.00533.x)

Suzuki N, Somei M, Seki A, Reiter RJ \& Hattori A 2008b Novel bromomelatonin derivatives as potentially effective drugs to treat bone diseases. Journal of Pineal Research 45 229-234. (https://doi. org/10.1111/j.1600-079X.2008.00623.x)

Szczepanik M 2007 Melatonin and its influence on immune system. Journal of Physiology and Pharmacology 58 (Supplement 6) 115-124.

Turgut M, Kaplan S, Turgut AT, Aslan H, Güvenç T, Cullu E \& Erdogan S 2005 Morphological, stereological and radiological changes in pinealectomized chicken cervical vertebrae. Journal of Pineal Research 39 392-399. (https://doi.org/10.1111/j.1600-079X.2005.00263.x)

Yoshihara H, Kawakami N, Matsuyama Y, Inoh H, Imagama S \& Ishiguro N 2005 A histomorphologic study of scoliosis in pinealectomized chickens. Spine 30 2244-2251. (https://doi. org/10.1097/01.brs.0000182095.00577.ee)

Zhang L, Su P, Xu C, Chen C, Liang A, Du K, Peng Y \& Huang D 2010 Melatonin inhibits adipogenesis and enhances osteogenesis of human mesenchymal stem cells by suppressing PPAR $\gamma$ expression and enhancing Runx2 expression. Journal of Pineal Research 49 364-372. (https://doi.org/10.1111/j.1600-079X.2010.00803.x)

Received in final form 12 April 2019

Accepted 30 April 2019

Accepted Preprint published online 30 April 2019 https://joe.bioscientifica.com https://doi.org/10.1530/JOE-18-0707 (c) 2019 Society for Endocrinology Published by Bioscientifica Ltd.
Printed in Great Britain 